\title{
DO POLÍTICO NO FUNCIONAMENTO DO MANIFESTO
}

\author{
ATILIO CATOSSO SALLES ${ }^{1}$ \\ Faculdade de Filosofia, Ciências e Letras Eugênio Pacelli \\ Universidade do Vale do Sapucaí \\ Av. Pref. Tuany Toledo, 470 - 37550-000 - Pouso Alegre - MG - Brasil \\ atiliocs@gmail.com
}

\begin{abstract}
Resumo. Como um gesto de leitura possível, encaro o desafio de ler a performance, enquanto analista de discurso, no lugar entre Arte e Análise de Discurso, que não significa um não-lugar, e sim, um lugar possível, lugaroutro de produção da interpretação. Para a produção de uma leitura discursiva, recorto como material de análise o documentário "The artist is present" (2010), produzido pela artista Marina Abramović. Nesse trajeto de pesquisa, interessaou também investir nas nuances da produção de sentidos para o corpo e para o quadro cênico nos estudos da performance. Outro movimento de análise proposto é o de explicitar como o político está presente no funcionamento discursivo do manifesto, no gesto de manifestar (escrever e ler sobre o método de formulação de uma performance).
\end{abstract}

Palavras-chave: arte; discurso; corpo; manifesto.

\begin{abstract}
As a gesture of possible reading, welcome the challenge of reading performance, while an analyst of discourse, in place between art and Discourse Analysis, which does not mean a non-place, and yes, a possible place, place-another production of interpretation. For the production of a discursive reading, cut out as material for analysis the documentary "The artist is present" (2010), produced by the artist Marina Abramovic. In this path of research, we have also invested in the nuances of the production of senses for the body and the scenic frame in performance studies. Another movement of analysis proposed is to clarify how the politician is present in the discursive functioning of the manifesto, in gesture to express (write and read about the method of formulating a performance).
\end{abstract}

Keywords: art; discourse; body; manifesto.

\footnotetext{
${ }^{1}$ Doutor em Ciências da Linguagem pela UNIVAS. Professor adjunto do Programa de Pós-Graduação em Ciências da Linguagem da UNIVAS.
} 


\section{INTRODUÇÃO}

O sujeito é sempre, e ao mesmo tempo, sujeito da ideologia e sujeito do desejo inconsciente e isso tem a ver com o fato de nossos corpos serem atravessados pela linguagem antes de qualquer cogitação.

(Paul Henry, A ferramenta imperfeita)

Ajustando as lentes, a fim de tentar compreender meu percurso de analista de discurso, questiono: o que me convoca, por vezes, a esse trabalho de olhar, ler, escutar, compreender o objeto simbólico arte? Intuo, enquanto possibilidade de resposta, que, de saída, se produziu uma urgência formulada pelo contato primeiro que tive com o campo das artes: literatura, música, teatro, fotografia, cinema, escultura. Ao produzir esse trajeto de pesquisa, senti-me ainda mais concernido à temática arte, também pela possibilidade que percebo na Análise de Discurso, enquanto uma disciplina de interpretação, de produção de um modo menos ingênuo de nos fazer ver/olhar o mundo.

Ver/olhar o que está nas telas, no palco, na rua, na periferia, nos textos, na imagem, nas galerias e fora delas. Olhar que traz consigo a marca, o vestígio, a presença de um sujeito que olha e é olhado e do mundo em que se inscreve.

\section{ANÁLISE DE DISCURSO E ARTE}

Retomo agora uma "charada" de criança que aponta para essa relação entre olhar e ver, fazendo-nos questionar: olhar ou ver? Tanto faz? Não acredito que seja indiferente esse jogo entre olhar e ver: "o que é, o que é, que quanto mais a gente olha menos a gente vê? O escuro."

Nesse caso, a determinação se elabora pelo excesso de visualização ("quanto mais a gente olha") que produz o efeito inverso ("menos a gente vê"). Com efeito, temos: quanto mais a gente vê, mais ainda há a produção de evidências em relação ao objeto simbólico. E isso se aplica não somente à materialidade da língua, a de que quanto mais se determina a língua, mais se indetermina o discurso, mas também a outras formas materiais que, por se inscreverem na história, não cessam de produzir sentidos. Eis o caso da performance.

Nessa direção, tratar da materialidade é ser consequente com a posição teórica que assumo na Análise de Discurso. Orlandi (1999) formula a noção de forma material enquanto uma forma linguístico-histórica, significativa. Nas palavras da autora:

Nós procuramos a materialidade - daí a insistência com a forma material (nem abstrata, nem concreta, nem empírica) na busca do real da língua e o real da história - para poder trabalhar a relação sujeito/sentido analisando as condições de produção (material) da vida política, social e elaborar a relação do imaginário com o real. (ORLANDI, 2012, p. 74) 
Nessa instância, a da materialidade, penso a performance em face da necessidade de pensar também o sujeito e os processos de leitura que o constituem. Michel Pêcheux (1984 [1998], p. 58), a respeito da tarefa do analista do discurso, diz que é: "expor ao olhar do leitor a opacidade do texto". Ou seja, expor a opacidade do texto (qual seja sua materialidade específica) ao olhar do leitor.

Considerando a performance, em sua forma material, em suas condições de produção, em que sujeitos e situação se configuram, em um funcionamento específico da memória, acredito que os sujeitos que participam da performance deixam sua marca, a marca mesma de uma passagem simbolizada no corpo-a-corpo, produzindo-se enquanto um processo discursivo inacabado, daí o movimento que se abre para a ressignificação. Deslocamentos. Esse processo de significação do sujeito com seu corpo em performance é parte da composição narrativa que o sujeito formula e pelo qual, de certo modo, também é formulado. Traçado de seu corpo em cena, este que não é abstração biológica, mas compreendido "pela interpelação ideológica do indivíduo em sujeito em sua materialidade e nos modos de sua individuação que presidem seu processo de identificação" (ORLANDI, 2015, p. 30). Ainda de acordo com Orlandi,

o discurso é produzido nessas condições, o sujeito e os sentidos, embora pareçam estar sempre lá, também são produzidos, e isto é efeito da ideologia em sua materialidade. $O$ corpo não é indiferente a isso. Enquanto corpo empírico, ele é apenas carne... (ORLANDI, 2002, p. 85)

Para pensar um pouco mais a relação de entre-lugar que vem se formulando pela combinação de Análise de Discurso e Arte, retomo o que Pêcheux, ao final do Anexo 3, formulou: "é preciso ousar se revoltar e é preciso ousar pensar por si mesmo" (1978 [1988], p. 304). Ao retomar essa elaboração de Pêcheux, compreendo que a Análise de Discurso é uma disciplina inquieta em relação ao próprio objeto. Por isso talvez a possiblidade de diálogo com a Arte se abre, se coloca possível, como tenho proposto neste trabalho.

Arte e discurso andam próximos no campo teórico da Análise de Discurso, e penso que isso não se deve colocar como motivo de estranhamento. Afinal, a Arte é tanto uma linguagem como também uma forma de subjetivação e, por isso, estabelece relação com o discurso. Por essa perspectiva, encontro espaço para inscrever a questão da arte como objeto discursivo, submetido à rede de conceitos que se opera no campo disciplinar do discurso.

\section{GESTO E INTERPRETAÇÃO DO ARQUIVO}

Recorto como objeto de análise para esta reflexão performances formuladas pela artista Marina Abramović. De saída, torna-se possível questionar: por que, neste trabalho, tomar como objeto discursivo de análise as performances de Marina Abramović? Parece-me, talvez, tratar de uma pergunta ingênua. Mas gostaria de tirar consequências disso.

Marina Abramović se autoproclama a avó da arte performática. Nascida em 29 de novembro de 1946, em Belgrado, a artista coloca-se entre as figuras de maior destaque na produção da arte performática no mundo. Em sua obra, é forte a questão da resistência 
física do corpo, pelo modo mesmo como isso está formulado em suas performances. Há, de certa maneira, enquanto regularidade norteadora de seus trabalhos, o jogo forte entre presença e ausência (trabalho do interdiscurso) que se elabora por diferentes formas materiais: a fotografia, instalações, vídeos, performances, documentários, filmes, que constituem assim um arquivo-arte sobre Abramović. Penso a noção de arquivo com Pêcheux (2010), como um lugar no qual se condensam determinados documentos - ou seja, arquivo é "[...] entendido, no sentido amplo, de 'campo de documentos pertinentes e disponíveis sobre uma questão"” (PÊCHEUX, 2010, p. 51). Logo, a noção de arquivo se coloca como um conjunto de documentos relacionados a um tema. Nesse caso, o tema arte. É nesse sentido que a obra de Marina Abramović constitui arquivo, se organiza por uma leitura. Não se trata de uma leitura analítica de arquivo, mas de uma leitura que aponta se determinados documentos são referentes a um tema $\mathrm{X}$ ou tema $\mathrm{Y}$.

Dentre os documentos que constituem o arquivo-arte sobre Abramović, temos publicações impressas que versam sobre "O Método Abramović", seu processo-arte de elaboração das performances e também de produções cinematográficas na web. A fím de apontar o modo como a artista constituiu/formulou seu método, trago um trecho do início do documentário "The artist is present" (2010), em que Abramović lê seu manifesto.

\begin{abstract}
Abramović: Escrevi meu manifesto de coração. Ele também é engraçado, ao mesmo tempo. Mas é verdadeiro.

Um artista não deve mentir a si mesmo ou a outros. Um artista não deve roubar ideia de outro artista. Um artista não deve se comprometer consigo mesmo ou com o mercado de arte. Um artista não deve matar outro ser humano. Um artista não deve se fazer de ídolo. Um artista está relacionado à sua vida amorosa...

Intérprete: Um artista está relacionado com sua vida real.

Abramović corrige: Não, vida amorosa. Amor. Amore.

[Risos]

Abramović: Um artista deve evitar se apaixonar por outro artista. Um artista deve evitar se apaixonar por outro artista. Um artista deve evitar se apaixonar por outro artista.
\end{abstract}

Nos primeiros minutos do documentário The artist is present (2010), Marina Abramović lê um manifesto em inglês enquanto sua fala é traduzida para o espanhol, que acima transcrevo, em português.

Nessa opacidade de sentidos produzidos pelo manifesto da artista, é interessante observar o tropeço ${ }^{2}$ do intérprete em:

Abramović: Um artista está relacionado à sua vida amorosa...
Intérprete: Um artista está relacionado com sua vida real.
Marina Abramović corrige: Não, vida amorosa. Amor. Amore.

Antes, se faz produtivo compreender esse trecho do documentário enquanto um ritual sujeito à falha(s). $\mathrm{O}$ manifesto, assim como a performance, é um ritual discursivo sujeito a falhas, em que faz movimentar sentidos e não-sentidos a partir, também, do silêncio fundante. Ao considerarmos o funcionamento discursivo do manifesto, o que irrompe,

\footnotetext{
${ }^{2}$ Tomo o tropeço como equívoco na relação com a ideologia.
} 
tropeça, vem significar a discursividade do ato de manifestar, em que a incompletude e a memória discursiva se enlaçam.

Nessa opacidade de sentidos produzidos no/pelo manifesto, interessa-me o silêncio, pois, segundo Orlandi, "quanto mais falta, mais silêncio se instala, mais possibilidades de sentidos se apresentam” (ORLANDI, 2007, p. 47).

A concepção de discurso é definida por Pêcheux como "efeito de sentidos entre locutores". Orlandi (2010, p. 15) aponta que tais efeitos "resultam da relação de sujeitos simbólicos que participam do discurso, dentro de circunstâncias dadas". Pêcheux (1996) retoma duas proposições de Althusser (1987) para fazer trabalhar a diferença entre formação ideológica, ideologia dominante e ideologia:

1. não existe prática, a não ser através de uma ideologia, e dentro dela;

2. não existe ideologia, exceto pelo sujeito e para sujeitos.

Sobre o conceito de ideologia em geral, Pêcheux (1996, p. 148) pondera que as relações de produção se elaboram entre os homens, "no sentido de não serem relações entre coisas, máquinas, animais humanos ou anjos". É o conceito geral de ideologia que abre a possibilidade de se pensar o homem como um animal ideológico.

Nesse gesto de análise, a compreensão de um traço forte em comum entre duas estruturas se coloca: a articulação da ideologia com o inconsciente. As estruturas ideologia e inconsciente operam ocultando sua própria existência, cosendo uma trama de evidências (verdades) significadas por certo sentido de subjetividade, que não engancham o sujeito, mas em que o sujeito se constitui, possibilitando o sujeito a formular: Um artista deve evitar se apaixonar por outro artista.

Às voltas com essa formulação, pensei o quanto Marina está presa à sua narrativa subjetiva, presa às tramas de escolhas que a fizeram redigir o manifesto, porque é esse o funcionamento de sua história particular e que a fixa neste tipo de inscrição-formulação:

- Um artista deve evitar se apaixonar por um outro artista.

- Um artista deve evitar se apaixonar por um outro artista.

- Um artista deve evitar se apaixonar por um outro artista.

Como todas as evidências - inclusive as que fazem com que uma palavra tenha um significado (evidência do sentido) e a evidência de que você e eu somos sujeitos (evidência do sujeito) -, é um efeito ideológico. Nesse limite, entre a constituição do sentido e a constituição do sujeito há "um vínculo que não é marginal". E, como já mencionei acima, considero o manifesto enquanto um ritual discursivo, em que se faz trabalhar ao mesmo tempo o "ritual" ideológico de escrever e ler na relação com a figura da interpelação - o indivíduo em sua escrita (e em seu gesto de leitura).

\section{DO POLÍTICO NO FUNCIONAMENTO DO MANIFESTO}

Gostaria, agora, de me deter em um caso, que é o de explicitar como o político está presente no funcionamento discursivo do manifesto, no gesto de manifestar (escrever e 
ler sobre seu próprio método). É preciso dizer que, na perspectiva teórica a que me filio, o político se define (ORLANDI, 1996) como divisão. Segundo Orlandi,

[...] o político está no fato de que tanto os sentidos como os sujeitos constituídos em determinadas condições de produção (circunstâncias da enunciação e contextos sócio-históricos) e inscritos em formações discursivas específicas - são divididos: em si e entre si. Portanto, é desta perspectiva do político, como divisão, que estamos falando, tendo como referência a relação com a(s) língua(s) e o conhecimento que se produz sobre ela(s), nas diferentes conjunturas das práticas políticas. (ORLANDI, 2014, p. 27)

Ao realizar uma pesquisa sobre o conceito de manifesto em diferentes dicionários, chamou-me atenção o fato de eles trazerem definições que cerceiam a ideia de evidência, clareza de ideias no gesto mesmo de manifestar. Segundo o Dicio: Dicionário Online da Língua Portuguesa: ${ }^{3}$

Declaração formal que, geralmente escrita, transmite intenções, opiniões, decisões ou ideias políticas, particulares a uma pessoa ou a um grupo de pessoas. Manifesto de apoio ao presidente.

Declaração divulgada publicamente com variados propósitos.

Documento com a lista de mercadorias transportadas que, antes do desembarque, deve ser entregue na alfândega.

Listagem de bens para fiscalização.

Para o Dicionário Aurélio ${ }^{4}$ as acepções de manifesto são:

1 Exposição (geralmente escrita) em que se manifesta o que é preciso, ou o que se deseja que se saiba.

2 Coisa manifestada.

3 Declaração feita à alfầndega, ou suas delegações, dos gêneros que se trazem sujeitos a direitos.

4 Dar ao manifesto: fazer essa declaração.

5 Patente, público, notório.

6 Evidente, claro.

O manifesto (assim como a arte) tem seu próprio regime de contradições. Este, enquanto ritual discursivo, sujeito a falhas, se inscreve na História (na medida mesma em que inscreve sujeitos) para significar. Em termos de significação, o ato de manifestar e de escrever um manifesto convoca sentidos de prescrição e advertência. Tais sentidos circulam também no dicionário.

E, acrescento, citando Pêcheux,

[...] que levar até às últimas consequências a interpelação ideológica como ritual supõe o reconhecimento de que não há ritual sem falha, desmaio ou rachadura: "uma palavra por outra" é uma definição (um

\footnotetext{
${ }^{3}$ Cf. Manifesto. In: Dicio: Dicionário Online de Português. Matosinhos: 7Graus, 2009-2017. Disponível em https://www.dicio.com.br/manifesto/. Acesso: 27 jan. 2015. (Grifos nossos.)

${ }^{4}$ Cf. Manifesto. In: FERREIRA, Aurélio Buarque de Holanda. Dicionário Eletrônico Aurélio Século XXI. Rio de Janeiro: Nova Fronteira/Lexikon, 1999. Versão 3.0. 1 CD-ROM.
} 
pouco restritiva) da metáfora, mas é também o ponto em que um ritual chega a se quebrar no lapso ou no ato falho. (PÊCHEUX, 1990, p. 17)

$\mathrm{Na}$ escuta desse material, na compreensão que abarca a polissemia "como diferentes movimentos de sentidos no mesmo objeto simbólico" (ORLANDI, 2012, p. 12), observo o funcionamento de efeitos ideológicos na própria equivocidade: do telespectador do documentário (e a plateia presente), quando somos atravessados pela noção de fato, de que a história $\mathrm{X}$ tenha sido, de verdade, vivenciada por aquela que está lendo e por aquela que escreveu o manifesto.

Nesse recorte, há ainda um outro lugar de ancoragem que aponta para uma equivocidade: "Escrevi meu manifesto de coração. Ele também é engraçado, ao mesmo tempo / Mas é verdadeiro". É o furo ou escape produzido pela adversativa mas, pelo uso do significante mas no manifesto de Marina que nos leva a formular a seguinte paráfrase: se quando escrito de brincadeira é falso.

Os diferentes processos pelos quais a língua se põe em ordem para fazer sentido é o que me chama atenção aqui. Sintaticamente, nos termos formalistas, o significado é um problema a que a estrutura do enunciado cabe resolver; discursivamente, o que interessa é a produção de sentido, são os efeitos de sentido que a formulação produz no momento em que acontece.

"Pela língua começa a confusão", Guimarães Rosa formulou. Não se pode negar a evidência da língua; diria também, não se pode negar a evidência da História. Isso, pois, no real da língua há a falha. Só se tem equívoco quando a falha própria da língua se inscreve na história; real da história.

Ela existe como tal, tem seu corpo, sua materialidade. Isto é inegável. Mas se pode desconfiar dela e de seu efeito de aparente transparência. Mais do que isso, é preciso investigar os mecanismos de funcionamento que produzem um sentido assim para língua. (LEANDRO FERREIRA, 1994, p. 6)

É a partir dessa reflexão que observo os efeitos de sentido produzidos pelo manifesto, em que o discurso de Abramović, afetada pela língua e pela História, ideologia e inconsciente, individuada pelo Estado e suas instituições, inscreve-se nas diferentes formações discursivas e explicita diferentes posições-sujeito ocupadas pela artista, performer, mulher.... Nesse sentido, retomo Pêcheux:

[...] só por sua existência, todo discurso marca a possibilidade de uma desestruturação-reestruturação dessas redes e trajetos: todo discurso é o índice potencial de uma agitação nas filiações sócio-históricas de identificação, na medida em que ele constitui ao mesmo tempo um efeito dessas filiações e um trabalho (mais ou menos consciente, deliberado, construído ou não, mas de modo atravessado pelas determinações inconscientes) de deslocamento no seu espaço: não há identificação plenamente bem sucedida, isto é, ligação sócio-histórica que não seja afetada, de uma maneira ou de outra, por uma 'infelicidade' no sentido performativo do termo - isto é, no caso, por um 'erro de pessoa', isto é, sobre o outro, objeto da identificação. (PÊCHEUX, 2002, p. 56-57) 
Para a análise de discurso, o deslizamento, a falha, a falta, não se coloca como um indício negativo, mas sim como lugar de resistência, forma do impossível de se dizer nem tão impossível e do não-sentido fazer sentido.

O equívoco ganha corpo e significação sob diferentes formas. Seu modo de materializarse pode ser pelo viés da falta, do parecido, do excesso, do non-sense e do repetido, como em:

\section{Abramović: Um artista deve evitar se apaixonar por outro artista. Um artista deve evitar se apaixonar por outro artista. Um artista deve evitar se apaixonar por outro artista.}

O que há de comum em todas essas formas de o equívoco se colocar é a ruptura do fio discursivo, que se dá no trabalho efetivo de se fazer e desfazer sentidos. Nas rachaduras deixadas pelos limites da língua é que encontramos as contradições, o absurdo, o nãosentido, o equívoco.... Retomo novamente a formulação abaixo:
Abramović: Um artista não deve mentir a si mesmo ou a outros. Um artista não deve roubar ideia de outro artista. Um artista não deve se comprometer consigo mesmo ou com o mercado de arte. Um artista não deve matar outro ser humano. Um artista não deve se fazer de ídolo. Um artista está relacionado à sua vida amorosa... Intérprete: Um artista está relacionado com sua vida real. Abramović corrige: Não, vida amorosa. Amor. Amore.

O discurso do ritual do manifesto se formula pelo comparecimento dos verbos "dever" e "estar", ambos conjugados na forma do presente do indicativo, uma locução verbal. O primeiro verbo vem acompanhado de um advérbio de negação, promovendo, enquanto efeito de sentido, a ideia de ordem, um estado permanente de uma situação: $o$ artista não deve mentir, não deve roubar, não deve... Aqui, a negação é a base da prescrição do manifesto. Essa é ordem sintática em que o manifesto é formulado. No entanto, em dado momento, o que irrompe é o verbo "estar": "Um artista está relacionado com sua vida amorosa". Isso não é continuação. Em termos de produção de sentidos, pode-se dizer que Marina Abramović, nesse momento, formulou de uma maneira que não é própria de um manifesto. Ou seja, foi pelo modo como a artista formulou que se criaram as condições de deriva produzidas pelo intérprete:

\section{Abramović: Um artista está relacionado à sua vida amorosa... Intérprete: Um artista está relacionado com sua vida real.}

Abertura para o equívoco. Quando Abramović saiu da ordem de escrita do manifesto, produziu-se um efeito sobre o intérprete, abertura de espaço para a interpretação. E isso se deu pela língua na relação com historicidade. Na língua, são produzem as condições pelas quais a própria língua se inscreve na história. De acordo com Indursky:

Derivar é romper com uma filiação, mas isso não implica esquecimento nem apagamento, pois os sentidos com os quais houve desidentificação continuam a ressoar desde o interdiscurso juntamente com os novos sentidos. (INDURSKY, 2013, p. 101) 
As formulações da língua podem escapar à organização da própria língua, ao trabalho da lógica e da razão: esse é o esforço que empreendi para compreender o funcionamento discursivo do manifesto - a ordem do manifesto. É nesse espaço que se localizam os tropeços e as faltas estruturantes próprias da língua. É o lugar que joga com a incompletude da linguagem, em que tanta coisa acontece e não acontece.

\section{O QUADRO CÊNICO DA “THE ARTIST IS PRESENT"}

O sentido não é exato (ORLANDI, 2012). Em consequência da análise da arte performática também cabe dizer: o espaço recortado para a produção de uma performance não é exato, é espaço praticado, é espaço político - ou seja, compreendido como divisão -, que ao mesmo tempo se abre para a estabilização e a desestabilização dos sentidos possíveis. Veremos isso na descrição que segue.

O Museu de Arte Moderna de Nova York, MoMA, foi fundado em 1929. Foi o primeiro museu que dedicou sua coleção somente à arte moderna. Com um espaço aproximado de 60 mil metros quadrados, dividido em seis andares, o MoMA recebe todos os anos várias exposições artísticas de estilos variados como expressionismo abstrato, arte metafísica e cubismo. Entre pinturas, esculturas, instalações e fotografias, o MoMA possui o maior o acervo de arte moderna do mundo.

Em 2010, Marina Abramovićfoi foi homenageada pelo MoMA com uma retrospectiva de sua carreira. Para essa exposição outros artistas foram convidados a reproduzir alguns dos trabalhos mais importantes de Abramović. Em especial para essa retrospectiva, a artista produziu a performance intitulada "The artist is present".

Ao longo da performance, com duração total de mais de 700 horas, Abramović ficou em uma cadeira por oito horas diárias, seis vezes por semana, durante três meses, enquanto visitantes eram convidados a sentar-se de frente para ela, em silêncio e pelo tempo que desejassem. A artista apenas fechava os olhos a cada vez que um visitante levantava, e voltava a abri-los quando outro ocupava o lugar. Vejamos algumas imagens da performance:

Montagem 5 - 0 quadro cênico da performance "The artist is present".

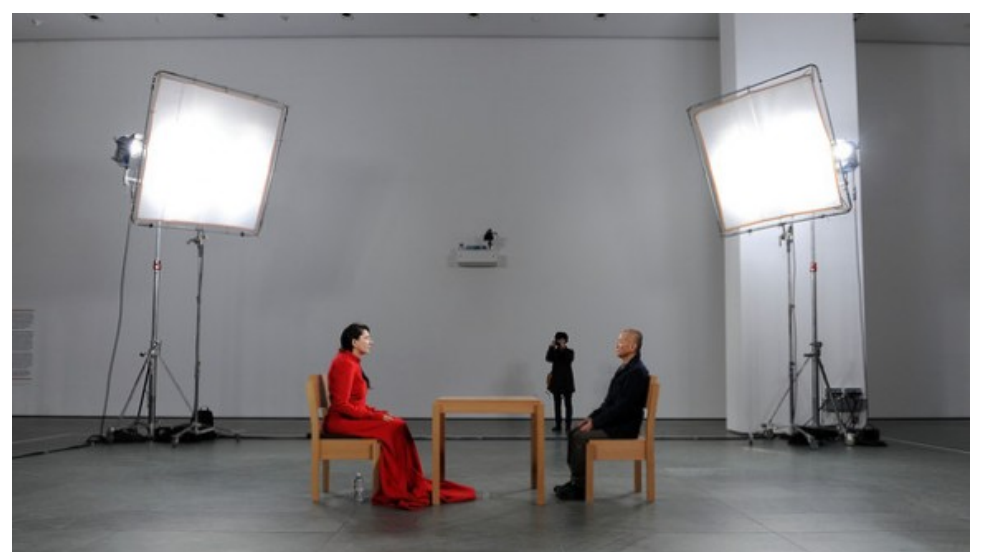




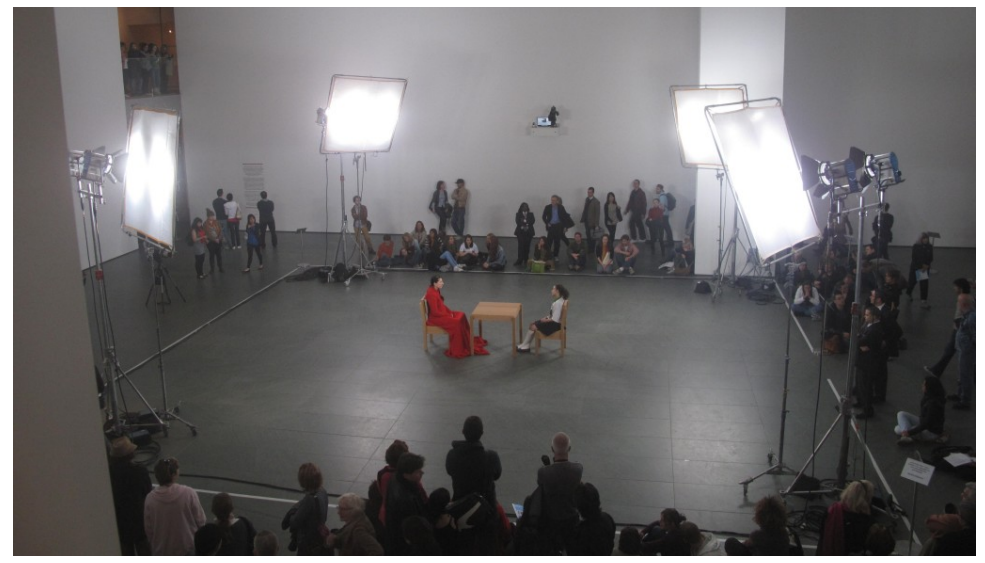

Fonte: The artist is present (2010).

A partir desses recortes é possível observar o modo como é constituído o quadro cênico da performance. À primeira vista é um espaço simples, demasiadamente simples, que a artista recorta. Um espaço quadrado no átrio do MoMA, delimitado por uma faixa branca, iluminado por refletores grandes, produzindo feixes de luz sobre duas cadeiras e uma mesa pequena, dispostas ao centro desse quadro cênico. Ao desconstruir e reconstruir o espaço físico há a produção de um direcionamento para a constituição de outros territórios de experimentação que se justapõem e se dobram uns sobre os outros e, nesse movimento, podem-se abrir potências de campos de significação, numa dobra de um espaço agora resignificado. Não é mais o átrio do MoMA, é um território outro.

Ora, nessa passagem, se faz necessário evocar o que entendo por território. Como ponto de partida, território não é aqui um mero lugar topográfico, físico, no qual a performance pode se dar a ver. A noção de território não vem primeiro, mas são as ações performáticas que recortam tal território. Em minha compreensão, território é o campo constituído por uma intrincada rede de materialidades discursivas. São lugares que não preexistem; o território é organizado, é traçado por um contorno de um centro incerto. Assim, compreendo que os territórios não preexistem. Os territórios se constituem ao mesmo tempo em que são produzidos, formas materiais que emergem compondo sentidos de novo espaço.

Segundo Deleuze e Guattari (1997), os processos de territorialização não são constitutivos de um sujeito, mas de um estilo. Em certa medida, aposto na existência de uma posiçãosujeito artista que produza a marca de uma passagem singular, produza existência, num movimento do qual emerja um "sentido". No entanto, é factível afirmar também, na arte performática em específico: instalamo-nos em territórios para deles poder fugir, traçamse pontos e linhas de desterritorialização para que algo ou alguém intervenha sobre o sentido ali instalado, como se o próprio território "tendesse a abrir-se para um futuro, em função das forças em obra que ele abriga" (DELEUZE; GUATARRI, 1997, p. 117).

De certa forma, quando Abramović convida os visitantes da exposição a participar da performance (sugerindo que ocupem a cadeira disposta em frente a ela e compartilhem um tempo indeterminado de silêncio), o espaço recortado do museu cartografa o território pelo modo mesmo como o corpo ali está implicado. O corpo em carne. Mas, além disso, 
o corpo em arte, o corpo que (se) significa diferentemente nesse quadro cênico. $\mathrm{O}$ corpo como possibilidade da performance.

Observa-se não o que o corpo da artista "é", mas "onde o corpo da artista está", que território ocupa. Ao se colocar numa situação de exposição - estática, sentada em uma cadeira no centro do quadro cênico -, a artista não necessariamente mostra seu território naquele momento, mas dá a ver um território que se compõe com a performance, com o corpo em performance. É possível detectar, então, de quais formas de expressão a artista com o seu corpo abre mão. Cartografa-se o território de Abramović - para depois poder fugir dele! $\mathrm{Ou}$, ainda, cartografa-se o território desse corpo estático, parado, sentado, que podemos também chamar de um corpo-em-arte, produzindo assim, nesse território, a potência de sua desconstrução, de sua re-significação.

Nessa direção, a performance "The artist is present" e a arte performática em geral abrem espaço para a produção de muitos deslizamentos metafóricos contingenciais. Alguns desses comentários (transcritos abaixo) foram produzidos durante alguns eventos científicos em que apresentei o documentário The artist is present; outros comentários foram formulados por espectadores em ocasiões particulares.

Marina, com o seu corpo, poderia durante a realização da performance falar algo.

Conseguiu trabalhar bem o corpo, mantendo-o estático.

É lindo ver ela compartilhando silêncio. O que pode significar isso?

O que tem atrás disso?

Não tem desafio.

Às vezes muito premeditado algumas coisas.

No início havia um leve movimento que rapidamente controlou.

Senti falta de algum gesto.

Gostaria de ver você se surpreender.

Gostaria de ver seu corpo se movimentando.

Como se pode perceber, o corpo instalado nesse território abre para um processo de interpretação contingencial, injungindo a um sempre possível processo de desestruturação-restruturação das redes e trajetos de identificação do sujeito com o sentido, vice-versa.

Não havendo 'encenação' bem-sucedida sobre esse outro, objeto nosso de identificação, o trabalho da desterritorialização (contida no próprio território) acontece, produzindo um desmanche sutil de pequenas coisas, do quase imperceptível para o aparecimento do singular de si mesmo. O espaço é deslocado.

Para Suely Rolnik (2006, 2012), cartografar um território implica em estar atento às estratégias das formações do desejo em qualquer fenômeno da existência humana. $\mathrm{O}$ cartógrafo

deixa o seu corpo vibrar em todas as frequências possíveis e fica inventando posições a partir das quais essas vibrações encontrem sons, canais de passagem, carona para a existencialização. Ele aceita a vida e se entrega. De corpo e língua. (ROLNIK, 2006, p. 66) 
Nessa tensão, nesse movimento próprio do território, do espaço cênico recortado, talvez possam se produzir fissuras de respiro. E por essas frestas de ar o corpo-em-arte re-existe.

\section{ALGUNS ENCAMINHAMENTOS FINAIS}

Na perspectiva discursiva, trabalha-se com alguns lugares de deslocamentos importantes como, por exemplo, as noções de linguagem, de sujeito, de ideologia e a de literalidade dos sentidos. Nesse lugar teórico, a) linguagem não é tomada como um código que se presta à mera transmissão de informações entre locutores ideais e/em situações ideais; $b$ ) o sujeito não representa o ponto de partida de seu dizer; c) a ideologia é constitutiva dos processos discursivos, não sendo possível descartá-la; e d) nos processos de linguagem não há a possibilidade de haver um/o sentido, ou seja, a literalidade não é o ponto de partida de uma reflexão linguageira.

Da compreensão sobre o espaço polêmico das maneiras de ler e a leitura de arquivo, fica um desafio: atentar para as correspondências que esses "arquivos" engendram em nós, o que de certa maneira se dá a partir de uma filiação nossa à memória histórica, um trabalho próprio do arquivo. Isso é considerar o arquivo em sua materialidade. Atentar também para o fato de que, no modo particular de produção dos discursos, em sua forma material específica, a textualização é determinada pelo processo de atualização dos sentidos no eixo horizontal, ou seja, no momento mesmo de sua circulação. Não se trata, portanto, de uma mera atualização da memória discursiva pela formulação no intradiscurso, mas da atualização do corpus pela circulação.

\footnotetext{
"Isso circula", como adquirimos o hábito de dizer, fazendo dessa circulação a imagem positiva de nossa modernidade discursiva liberada, ou ao contrário, a falsa moeda das línguas de vento: os turbilhões esfumaçados do "não importa o que" destinados a chamar a atenção, desviando-a dos "problemas reais". Não seria tempo de destituir essa imagem duplamente satisfatória da circulação, assumindo o fato de que as circulações discursivas não são jamais "não importa o quê?" (PÊCHEUX, 1981, p. 18)
}

É a partir desse trajeto que inscrevo minhas questões de pesquisa. Para Pêcheux o trabalho de compreensão discursiva se coloca na tensão de "abalar a religião dos sentidos". Vê-se, portanto, que não trato aqui da dimensão do significado, mas sim da significação do manifesto na dimensão do significante. Nessa tomada, o que interessa de modo mais forte é o que nos escapa a esses processos de escrita e de movimentos em jogo instalado na leitura do manifesto, numa sequência de gestos e procedimentos, no momento de sua realização.

Nessa direção é que a Análise de Discurso se distancia das evidências da materialidade discursiva, para então produzir um trabalho de compreensão sobre os efeitos que irrompem dessa materialidade.

\section{REFERENCIAS}

ABRAMOVIĆ, Marina. Doc. The Artist Is Present, 2012. 
ALTHUSSER, L. Aparelhos ideológicos de Estado. 3a. ed. Rio de Janeiro: Graal, 1987.

DELEUZE, Gilles; GUATTARI, Félix. Mil Platôs: capitalismo e esquizofrenia. vol. 4. Trad. de Suely Rolnik. São Paulo: Editora 34, 1997.

INDURSKY, Freda. O trabalho discursivo do sujeito entre o memorável e a deriva. Signo y Seña, n. 24, pp. 91-104, dic. 2013.

LEANDRO FERREIRA, M.C. O corpo enquanto objeto discursivo. Em: PETRI, V.; DIAS, C. (Orgs.). Análise de Discurso em perspectiva: teoria, método e análise. Santa Maria: Editora da UFMS, 2013.

LEANDRO FERREIRA, M.C. A resistência da língua nos limites da sintaxe e do discurso: da ambiguidade ao equívoco. Tese (Doutorado em Linguística), Instituto de Estudos da Linguagem, Universidade Estadual de Campinas, Campinas, 1994.

ORLANDI, E.P. Ciência da linguagem e política: anotações ao pé das letras. Campinas: Pontes, 2014.

ORLANDI, E.P. A materialidade do gesto de interpretação e o discurso eletrônico. Em: DIAS, C. (Orga.). Formas de mobilidade no espaço e-urbano: sentido e materialidade digital. v. 2, 2013. (Série e-urbano). Disponível em: http://www.labeurb.unicamp.br/livroEurbano/volumeII/arquivos/pdf/eurbanoVol2 EniOrlandi.p df. Acesso: 14 fev. 2017.

ORLANDI, E.P. Discurso em Análise: sujeito, sentido e ideologia. Campinas: Pontes, 2012.

ORLANDI, E.P. Interpretação: autoria, leitura e efeitos do trabalho simbólico. $6^{\text {a }}$. ed. Campinas: Pontes, 2012.

ORLANDI, E.P. A contrapelo: incursão teórica na tecnologia: discurso eletrônico, escola, cidade. RUA, $\quad$ n. $16, \quad$ v. $\quad 2, \quad 2010 . \quad$ Disponível $\quad \mathrm{em}$ https://periodicos.sbu.unicamp.br/ojs/index.php/rua/article/view/8638816. Acesso: 24 abr. 2017. ORLANDI, E.P. Discurso e Texto: formulação e circulação dos sentidos. $3^{\mathrm{a}}$. ed. Campinas: Pontes, 2008.

ORLANDI, E.P. Textualização do corpo: a escritura de si. Cidade dos Sentidos. Campinas: Pontes, 2004.

ORLANDI, E.P. Coreografar: inscrever significativamente o corpo no espaço. Em: FERREIRA, E.L. et. al. (Orgs). Interfaces da dança para pessoas com deficiência. Campinas: CBDCR, 2002.

ORLANDI, E.P. Dança e Discurso. Em: SIMPÓSIO INTERNACIONAL DANÇA EM CADEIRA DE RODAS, I, Campinas. Anais [...], Curitiba: ABRADECAR, 2001.

ORLANDI, E.P. As formas do silêncio: no movimento dos sentidos. $3^{\text {a }}$. ed. Campinas: Editora da Unicamp, [2007- 1997] 1995-1999.

ORLANDI, E.P. A linguagem e seu funcionamento: as formas do discurso. Campinas: Pontes; 1996.

ORLANDI, E.P. Segmentar ou recortar? Linguística: questões e controvérsias. Curso de Letras do Centro de Ciências Humanas e Letras das Faculdades Integradas de Uberaba, 1984. (Série Estudos, 10)

PÊCHEUX, M. Ideologia: aprisionamento ou campo paradoxal? Análise de discurso. Textos escolhidos por Eni Orlandi. Campinas: Pontes, 2011.

PÊCHEUX, M. Papel da memória. Em: ACHARD, P. et al. Papel da memória. Tradução e Introdução de José Horta Nunes. Campinas: Pontes, 2010.

PÊCHEUX, M. Semântica e discurso: uma crítica à afirmação do óbvio. Trad. Bras. $4^{\mathrm{a}}$. ed. Campinas: Pontes, [1975] 2009.

PÊCHEUX, M. Só há causa daquilo que falha ou o inverno político francês: início de uma retificação. Semântica e discurso: uma crítica à afirmação do óbvio. Campinas: Ed. da Unicamp, [1969, 1997] 2009.

PÊCHEUX, M. O Discurso: estrutura ou acontecimento. Trad. Bras. $3^{\text {a }}$. ed. Campinas: Pontes, [1990] 2002, 2008.

PÊCHEUX, M. O mecanismo do desconhecimento ideológico. Em: ZIZEK, S. Um mapa da ideologia. Rio de Janeiro: Contraponto, 1996. 
PÊCHEUX, M. Ler o arquivo hoje. Em: ORLANDI, E. (Org.). Gestos de leitura: da história no discurso. Campinas: Editora da Unicamp, 1994. p. 55-64.

PÊCHEUX, M. Análise automática do discurso (AAD 69). Em: GADET, F.; HAK, T. (Orgs.). Por uma análise automática do discurso: uma introdução à obra de Michel Pêcheux. $4^{\mathrm{a}}$. ed. Campinas: Editora da Unicamp, 1993.

PÊCHEUX, M. Delimitações, inversões, deslocamentos. Cad. Est. Ling., Campinas, jul./dez. 1990.

PÊCHEUX, M. Ouverture du colloque. In: CONEIN, B. et. al. (Orgs.). Matérialités discursives. Lille: Presses Universitaires de Lille, 1981. p. 15-18.

PÊCHEUX, M.; FUCHS, C. A propósito da análise automática do discurso. Em: GADET, F.; HAK, T. (Orgs.). Por uma análise automática do discurso. Campinas: Editora da Unicamp, 1990. p.163-252.

PÊCHEUX, M.; LÉON, J. Análise sintática e paráfrase discursiva. Em: ORLANDI, E.P. (Orga.). Análise de Discurso: Michel Pêcheux. Campinas: Pontes, [1982] 2011. p. 163-173.

ROLNIK, S. Cartografia Sentimental. Porto Alegre: Editora da UFRGS, 2006.

ROLNIK, S. Clínica Nômade. Em: EQUIPE de Acompanhantes Terapêuticos do Hospital-Dia A Casa. Crise e cidade: acompanhamento terapêutico. São Paulo: Educ, 1997. pp. 83-87.

\section{Outras referências}

Manifesto. Em: Dicio: Dicionário Online de Português. Matosinhos: 7Graus, 2009-2017. Disponível em: https://www.dicio.com.br/manifesto/. Acesso: 27 jan. 2015.

Manifesto. Em: FERREIRA, Aurélio Buarque de Holanda. Dicionário Eletrônico Aurélio Século XXI. Rio de Janeiro: Nova Fronteira/Lexikon, 1999. Versão 3.0. 1 CD-ROM.

"MANIFESTO sobre a vida do artista", por Marina Abramovich. arte|ref: referência e notícia em arte contemporânea, [s.1.], 25 set. 2013. Disponível em http://arteref.com/gente-dearte/manifesto-artistico/. Acesso: 20 mar. 2016.

Artigo recebido em: jan. de 2019.

Aprovado e revisado em: abril de 2019.

Publicado em: dezembro de 2019.

Para citar este texto:

SALLES, Atílio Catosso. Do político no funcionamento do manifesto. Entremeios [Revista de Estudos do Discurso, ISSN 2179-3514, on-line, www.entremeios.inf.br], Seção Estudos, Programa de Pós-Graduação em Ciências da Linguagem (PPGCL), Universidade do Vale do Sapucaí (UNIVÁS), Pouso Alegre (MG), vol. 18, p. 3-16, jan. - jun. 2019.

DOI: http://dx.doi.org/10.20337/ISSN2179-3514revistaENTREMEIOSvol18pagina3a16 